\title{
Revision of Benedeniella Johnston, 1929 (Monogenea: Capsalidae), its assignment to Entobdellinae Bychowsky, 1957 and comments on subfamilial composition
}

\author{
IAN D. WHITTINGTON ${ }^{1,2,3}$ \\ ${ }^{\prime}$ Monogenean Research Laboratory, Parasitology Section, The South Australian Museum, North Terrace, Adelaide, South Australia \\ 5000, Australia.E-mail: ian.whittington@samuseum.sa.gov.au \\ ${ }^{2}$ Marine Parasitology Laboratory, School of Earth and Environmental Sciences (DX 650 418), The University of Adelaide, North \\ Terrace, Adelaide, South Australia 5005, Australia \\ ${ }^{3}$ Australian Centre for Evolutionary Biology and Biodiversity, The University of Adelaide, North Terrace, Adelaide, South Australia \\ 5005, Australia
}

\begin{abstract}
Benedeniella macrocolpa (Lühe, 1906) Yamaguti, 1963 is redescribed from new material collected from ventral skin surfaces of the Australian cownose ray, Rhinoptera neglecta Ogilby (Elasmobranchii: Myliobatidae) from waters in Moreton Bay and from captive rays in a public display aquarium in Townsville, from $R$. cf. neglecta and Rhinoptera sp. from Weipa, Queensland, Australia and from R. javanica Müller \& Henle caught in the Arabian Gulf north of Dubai, United Arab Emirates. Benedeniella posterocolpa (Hargis, 1955) Yamaguti, 1963 is redescribed from new specimens collected from the cownose ray, R. bonasus (Mitchill) (Myliobatidae) from several localities in the Gulf of Mexico and in the Chesapeake Bay region of the south-eastern and eastern USA, respectively. Detailed anatomical redescriptions demonstrate that each Benedeniella species share several dorsal structures (paired anterior horns, excretory papillae and posterior conical structures at the junction of the body with the haptor), anterolateral grooves on the ventral surface of each anterior attachment organ, a similar route for tendons associated mostly with the accessory sclerites and the anterior hamuli and a long vagina. The different path of the vagina and the position of the vaginal pore are the simplest characters to discriminate the two species. Benedeniella unnithani Gupta \& Chanana, 1976 from the gills of a Caranx sp. (Teleostei: Perciformes: Carangidae) off Kavaratti, Laccadive Islands, Arabian Sea, India is considered a species incertae sedis. Morphological parallels are identified, in particular concerning the anterior attachment organs of species in Benedeniella, Branchobdella Kearn, Whittington \& Evans-Gowing, 2007, Entobdella Blainville in Lamarck, 1818, Neoentobdella Kearn \& Whittington, 2005 and Pseudoentobdella Yamaguti, 1963. Of these entobdelline genera, species in three of them parasitise principally the skin of elasmobranch rays (Dasyatidae; Myliobatidae; Rhinobatidae); only species in Branchobdella and Entobdella parasitise flatfish teleosts (Paralichthyidae; Pleuronectidae; Soleidae). On the basis of the redescriptions presented here plus morphological similarities, host associations and recently published molecular genetic data, Benedeniella is moved from the Benedeniinae Johnston, 1931 and the diagnosis for the Entobdellinae Bychowsky, 1957 is amended to unite Benedeniella, Branchobdella, Entobdella, Listrocephalos Bullard, Payne \& Braswell, 2004, Neoentobdella and Pseudoentobdella. The affinities of species in a seventh capsalid genus, Trimusculotrema Whittington \& Barton, 1990 (currently in Benedeniinae), are considered briefly based on morphology and host association and reassigned to the Entobdellinae.
\end{abstract}

Key words: Platyhelminthes, Monopisthocotylea, Benedeniinae, Entobdellinae, Benedeniella macrocolpa, Benedeniella posterocolpa, Trimusculotrema species, elasmobranch hosts, Myliobatidae, Australia, United Arab Emirates, United States

\section{Introduction}

The Capsalidae Baird, 1853 (Platyhelminthes: Monogenea: Monopisthocotylea) comprises nine subfamilies (Whittington 2004) and approximately 180 species (Perkins et al. 2009). Whittington (2004) noted some of the advances to establish the validity and composition of some capsalid subfamilies. For example, in the 